count, but the individual erythrocyte has undergone a change so that it resembles the cells in normal blood, which I have called, for want of a better name, old cells. In many cells the cytoplasm in stained specimens seems pushed out to the periphery to such an extent that the cell becomes dumbbell-shaped instead of the normal lenticular or biscuit shape. As a result the cells pack together closely and show a marked diminution in volume by the hematokrit. The oxygen-carrying capacity is lowered, and in consequence the hemoglobin is deficient in color test. The blood in neurasthenia then would seem to be poor in oxygen-carrying capacity and not only this, but, owing to the poor vasomotor control, the peripheral blood at least varies much in its character. Time and again I have noticed the blood issuing from a puncture, not well mixed so that serum came first and then, apparently, a mass of corpuscles. Such findings lead at once to speculation. Certainly many cases of neurasthenia have some form of toxemia as an underlying cause. The value of all means of hemogenesis is at once apparent and, if it were necessary, further proof is furnished for the value of massage, electricity and overfeeding.

\section{INTUBATION OF THE LARYNX, WITH PERSONAL REMINISCENCES.*}

\section{F. E. WAXHAM, M.D.}

Professor of Medicine, Clinical Medicine and Laryngology, Medical Department Colorado State University. DENVER, COLO.

March 20, 1885, it was my privilege to present a paper on the intubation of the larynx to the Chicago Medical Society, and to illustrate the operation on the cadaver. Through the courtesy of Dr. Joseph O'Dwyer, of New York, now deceased, who was experimenting with this operation in the hospitals of that city, I was provided with the crude and primitive instruments then in use.

My first operation was performed April 19, 1885, on a child 2 years old, choking to death with diphtheritic croup. My assistants were an old lady, who held the patient on her lap, and a boy 12 years old, who held the gag and steadied the head. I had never seen the operation done, yet, with these poor and untrained assistants, the tube was successfully introduced on the third attempt, giving prompt and immediate relief. This was the first intubation performed west of New York City, and probably the first ever done in private practice. Previous to this time the mortality of diphtheritic croup, without surgical interference, was almost 100 per cent. It was the most fatal and the most dreaded of all diseases of childhood. Occasionally a patient would struggle through the disease, but it was a rare event. I well remember having been called to a boy, 10 or 12 years old, who was choking to death with this disease. $\mathrm{He}$ was rolling and tossing about the bed, purple, gasping for breath, and clutching at the throat in a vain attempt to find relief. I begged, implored and argued with the mother, an Irish dame, for permission to open the trachea to give the poor lad relief. She obstinately refused, saying: "I would ruther see me bye die than have his wind pipe cut." This statement illustrates the prejudice that prevailed against tracheotomy.

I took my departure, after prescribing an emetic, not being willing to stand idly by, with hands tied, to see the boy strangle to death. A few days later I learned that

* An address, delivered on request, before the Denver and Arapahoe County Medical Society. Dec. 11, 1900. he was well. In his last violent effort for life he succeeded in expelling a membranous cast of the larnyx and trachea and recovered. Those of us who practiced medicine in those days, know full well that such recoveries were very rare, almost like "angels' visits." When tracheotomy was performed the mortality was somewhat reduced. It was generally estimated that in wellselected cases it amounted to about 75 per cent.; but in private practice I had saved but one out of twenty operations, and of 300 operated on in Chicago, the recoveries had been only 9 per cent., a mortality of 91 per cent. Confronted by these facts and this fearful mortality, I felt justified in taking any risk, however great, in the hope that better results might be attained.

My first case terminated fatally. My second operation was performed April 23, 1885. The tube, which was one of the early ones, with a very small rim at the top dropped through the glottis, and I lost not only my tube, but my patient as well. This incident led to the enlargement of the head and a similar accident has never since occurred.

Mv third operation was on July 16, and likewise, resulted fatally. My patients troubled me greatly by coughing up the tubes every few hours, necessitating their frequent reintroduction. Dr. O'Dwyer, with whom I was keeping up a brisk and most kindly correspondence, suggested a shoulder on the tube, to overcome this difficulty. I therefore, had the tubes made with a projecting shoulder, about three-quarters of an inch below the head; this was subsequently modified by the bulge or swelling in the center of the tube, with which all are familiar, and which to a certain extent overcomes this objection.

My fourth operation was done Sept. 15, 1885, and was successful. The child wore the tube five days. This, as far as I know, was the first patient in private practice to recover, and was a great encouragement, not only to myself, but to Dr. O'Dwyer, as we were both becoming disheartened. By November, 1885, I was able to report eleven cases to the Chicago Medical Society, with four recoveries. From this time on cases multiplied rapidly, as did also my trials and tribulations. Demands came from all parts of Chicago and its suburbs for the operation. and life became a burden.

I recall, among others, a case to which I was called in great haste and at much inconvenience, only to be informed on arrival that the father had decided not to allow an operation. The boy, 5 or 6 years old, was in great distress, suffering all the agonies of slow strangulation. I insisted on the operation in no uncertain terms, and finally the father inquired how much I would charge. I told him it did not matter; would relieve the boy first and talk about the fee later, but he insisted on knowing and when I said I would not charge more than $\$ 25$ he said: "If you want to do the operation so bad go ahead and do it. If he gets well I will pay you $\$ 25$, but if he dies you have got to pay me $\$ 25$." This was a new proposition, but I agreed, and in less time than it takes to tell it the child was relieved; however. the patient subsequently died from the extension of the disease. In another case the father disputed a bill of $\$ 25$, informing me that all I did was to "run a tube down the child's neck, and that he could have done it himself; it was nothing but robbery" and I could have $\$ 5$ or nothing. Feeling that this was a small sum for a life-saving operation, it was declined.

In another case the father declined to pay a small fee after two weeks of the most faithful attendance because, as he said, "a brass tube was used, which poisoned 
the child and caused its death." About this time the coroner was called to investigate one of my cases. It was said that I put plugs in the childrens' throats, and that was what killed them. One of my livliest experiences occurred about this time. I was called one night to remove a tube from a desperate case of diphtheria, on which I had operated a few days before. It was in the dead of night and in one of the tough districts of the city. The patient was desperately ill, and the only hope seemed to be in removing the tube, and while this was quickly and easily done, yet the child suddenly expired in the arms of the assistant from paralysis of the heart. Nothing could convince the father that I had not killed the child, and a hasty retreat was in order. I was followed by a shower of bricks and stones and, with the irate father at my heels, fleetness of foot was all that saved me. During these days my life was frequently threatened by hard, ignorant and tough characters, and it was necessary to go armed, not knowing but that these threats might be carried out any dark night. It appeared to me about time to quit, for in payment for my time and strength and discomfort and risks I rarely received anything but abuse and threats of dire vengeance. Had the city been a smaller one my reputation would have been ruined, but fortunately my patients were so widely scattered that I was still able to hold my own. Dr. O'Dwyer, writing me at this time, said: "I do not know which to admire most, the skill required in doing the operation or the courage in introducing it into private practice." Many and many a time I have said that I would not do the operation again, but this resolve would be no sooner made than there would come an urgent call. from some physician who would not be refused, and so the resolve would be broken. An occasional life saved, occasional evidences of the deepest and greatest appreciation and the consciousness that more lives were being saved than by any other known means, enabled me to keep up the work when, otherwise, strength and courage would have failed. I had other trials as well, for it was only natural that any innovation should meet with the disapprobation of many conservative members of our profession. Many a heated discussion occurred over the subject of intubation, as I reported my cases from time to time. The most bitter debate was at the meeting of the AMFrican Medical Association, held in Chicago in 188\%. One of my staunchest and truest friends was Dr. Charles Warington Earle, now deceased, whose magnificent ability, voice and physique many will remember, and whose watchword in every fight was, "Come on boys." He was one of the early converts to the utility of intubation and its superiority over tracheotomy. He never did the operation, but in every debate his voice was raised in its favor. As a result of the bitter discussion over this subject, at the meeting referred to, a committee was appointed, consisting of Larrabee, of Kentucky, and Jones, of Illinois, to visit my patients and report the results of their investigation through THE JoURNaL. After seeing some of the patients who had recovered, others wearing the tubes and operations on others, a most enthusiastic report was made in favor of intubation. ${ }^{1}$ Since then there has been but little opposition to the operation. I am convinced that it is a difficult one and that there are but few who can perform it well without long and careful training. To me it has never been difficult, excepting in two instances, and this after a very large

1. The discussion and report will be found in THE Jounnal A. M. A., of July 30, 1887 . experience. In these it was due to subglottic infiltration, and in one tracheotomy was required, while in the other the tube finally crowded through after great difficulty. Dr. O'Dwyer met with the same experience in one or two cases. It is a condition that must be very rare, as in several hundred I have met with but these two.

In my brief experience I have seen the mortality of diphtheritic croup almost 100 per cent. without surgical interference. With tracheotomy I have seen it reduced to 75 to 90 per cent.; with the introduction of intubation, to 60 to 75 per cent.; and finally, with intubation supplemented by antitoxin, I have seen this great mortality reduced to almost nothing. It is now sometimes asked if intubation is not unnecessary when we have a specific remedy in antitoxin. It is true that many operations are unnecessary when antitoxin is given early and repeatedly in large doses. It is true that it at once arrests the progress of the disease, but it is also true that many are neglected and not seen by the physician until the larynx has been invaded and the only possible hope is in an immediate operation. Many again commence as a laryngeal diphtheria and death may occur from suffocation before we can get the specific effect of antitoxin. While it prevents further extension of the disease, it does not immediately cause the destruction or disappearance of the obstructing membrane already present. I well remember a case in point, and a most exciting race for life, in which death for once was defeated, although by a narrow margin. One night I received a message from a doctor some miles distant, informing me that his patient, a boy 5 years old, was in a dying condition from diphtheritic croup, although he had given antitoxin. He. implored me to make all possible haste, as it was doubtful if the boy could live over a few minutes. He said he would keep up artificial respiration and endeavor to keep him alive until I could arrive. Hurrying thither, I found the little spark of life still fluttering, although the child was purple, unconscious and in the last convulsive death agony. The jaws were pried apart and the gag inserted with great difficulty, but the tube was quickly placed and the child revived, and is living and well today.

In my first 100 cases there were but $2 \pi$ recoveries; in the second, 34; in the third, 40; in the fourth, 38, and in the fifth, 39 , while of my last $\% 0$ operations, in connection with antitoxin, there have been but 4 deaths, a mortality of less than 6 per cent. in a disease that formerly was dreaded above all others. With this experience I feel justified in saying most emphatically that any medical man who does not use antitoxin in the treatment of dinhtheritic croup is guilty of malpractice, and he who openly opposes its use should be considered a menace to society, for "there are none so blind as those who will not see and none so deaf as those who will not hear."

I can not close without again paying my tribute of honor to the memory of Dr. Joseph O'Dwyer. His name will ever appear among the honored ones in the history of medicine. I have seen the mortality of diphtheritic croup reduced from almost 100 per cent. without operation to almost nothing with intubation supplemented by antitoxin.

For the distressing annoyance caused by the itching and tingling of chilblains, Chaffee applies tincture of iodin directly to the affected parts for two or three nights, which gives quick and complete relief. 